\title{
Clara Clara
}

$\mathbb{N}$ UM FILME antigo de Totò, célebre comediante italiano (Totò, Peppino e a malafemmina, 1956), dois napolitanos, na véspera de ir para Milão, aprendem que lá há a neblina, que faz que "não se veja nada". Ao descer do trem, num dia perfeitamente sereno, um dos dois exclama: "Que neblina!". E quando o outro reclama que não está vendo nada, replica: "Justamente". A piada é boa: se o efeito da neblina fosse tornar impossível a visão, deveria ser ela mesma invisível. Mas a neblina é bem visível e, como qualquer corpo opaco, encobre o que está atrás dela. Dizemos que não vemos nada porque não olhamos para ela, apenas através dela, e não conseguimos ver o que queríamos. Aliás, se a neblina fosse completamente opaca, se não nos prometesse mostrar os objetos que afinal esconde, não proporcionaria uma sensação tão clara de perda da visão. O que faz que na neblina não se veja nada é que nela, afinal, alguma coisa se vê.

Por outro lado, é um lugar-comum desde a filosofia antiga que a luz exerça uma dupla ação: ao mesmo tempo que torna visíveis as coisas, torna visível a si mesma. Analogamente, nossa mente torna-se perceptível não por uma imagem ou pensamento específico, mas ao produzir imagens e pensamentos de outras coisas. Haveria então um paralelismo entre pensamento e iluminação, justificado inclusive pela etimologia (o termo grego por representação mental, phantasia, derivaria de luz, phôs). Mas a tese é verdadeira só se falarmos em visão num sentido muito amplo: na realidade, nunca vemos a luz em si, a não ser em situações muito particulares, como em experimentos científicos. O que vemos são objetos iluminados e fontes luminosas. Analogamente, é raro pensarmos no pensamento. Luz e pensamento não são propriamente objetos da visão ou da representação, mas algo que acompanha necessariamente toda imagem. Não podemos dizer que os deduzimos posteriormente: dão-se de imediato. Mas também não se incorporam totalmente ao objeto: se prestarmos atenção a eles, embaralham um pouco a vista. Nesse sentido, se a luz é metáfora do pensamento como meio de representação, a neblina poderia ser metáfora do pensamento como ruído que cerca toda representação.

Até onde poderíamos levar esse raciocínio? Há uma neblina conotativa entre nós e as coisas, que borra a pureza do estímulo óptico: vemos o frio num bloco de gelo, o calor numa nuvem de vapor, o tempo numa pedra erodida, o vazio na distância entre os objetos (ou será a distância no vazio?). Aqui também, não se trata de meras inferências: a percepção visual é imediatamente fria ou quente, demorada ou instantânea, cheia ou vazia. Uma longa tradição estética nos ensinou a desconsiderar esses aspectos: o branco é branco, não interessa se neve ou linho; o vermelho, sangue ou maçã, é vermelho.

A obra de Laura Vinci, ao contrário, circula por essa terra de ninguém, onde o ato de visão ainda é íntegro, mas já começa a se decompor em qualidades. $\mathrm{O}$ vazio, o tempo, a atmosfera, a temperatura são questões centrais para ela. Se, 
por exemplo, verdadeiras maças são dispostas sobre uma mesa de mármore, junto com pequenas esculturas também em mármore (Ainda Viva, São Paulo, Galeria Nara Roesler, 2007), não é apenas uma contraposição de vermelho e branco, redondo e poligonal, que está em jogo, mas a relação entre dois "tempos" diferentes da cor e da forma: o branco e os contornos do mármore são estáveis; o vermelho e a esfericidade das maçãs alcançam um ápice, depois murcham. Há uma tensão no vermelho e uma paz no branco, uma solidez no polígono e uma maciez na esfera, que não são mera questão de geometria e gama cromática. O mármore, na nossa cultura, está ligado ao clássico, à permanência, ao ideal; a maçã é símbolo da tentação, do sensível, do átimo que foge e deve ser colhido. $\mathrm{E}$ finalmente, maçãs sobre uma mesa, para todos nós, querem dizer Cézanne, ou seja: uma pintura que se refaz continuamente e nunca acaba.

Convém nos determos um pouco nisso, antes de abordar a questão que Clara Clara enfrenta: a luz. O mármore aparece pela primeira vez numa instalação de 2000, no Centro Universitário Maria Antonia, na dupla forma de esculturas arredondadas, que a artista chamou de Brancusas, e de pó amontoado, onde afundavam e que em parte as recobria. O pó, por sua vez, remete ao monte de areia da instalação sem título realizada três anos antes nas Oficinas Matarazzo, por ocasião de Arte Cidade 3. Esse trabalho, certamente seminal na obra de Laura Vinci, já foi muito comentado. Aqui, será suficiente salientar o contraste entre a areia amontoada e o esqueleto do prédio em ruína. O prédio estava virando pó. A areia, por outro lado, já é pó e não mais se transforma, é um es-

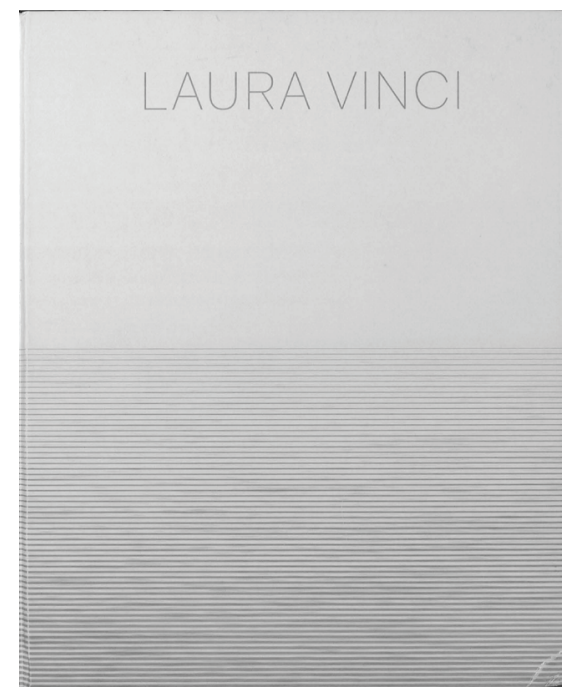

VINCI, L. Laura Vinci-Vários autores. São Paulo: Cosac Naif; Associação para o Patronato Contemporâneo, 2013. 216p.

tádio final. De certa maneira alcançou a eternidade, só muda de lugar porque todo lugar lhe é indiferente. Os prédios, ao contrário, ruem porque são história, intenção de duração, necessariamente fadada ao fracasso. Entre os dois extremos, o fio de areia, coando para o andar de baixo, marcava o tempo.

Por sua vez, as Brancusas do Centro Maria Antonia, arredondadas, brancas, pareciam indestrutíveis. Poderiam se consumir, reduzindo-se imperceptivelmente, mas não serem quebradas, porque não tinham arestas. Pela remissão a Brancusi, aludiam à história da arte, como o prédio das Oficinas Matarazzo remetia à história tout court. Remetiam, mais precisamente, a um artista que trabalhava as pedras como o tempo as erode, alcançando inesperadamente, em plena idade moderna, um momento de conciliação entre natureza e arte. Mas esse momento só pode ser retomado se der conta de seu complemento necessá- 




Intervenção que utiliza elementos de iluminação pública de forma orgânica. 
rio, a matéria que foi sacrificada à conciliação. Como pedras enterradas na areia, as Brancusas são protegidas pelo mesmo pó em que se consumam.

Aquela obra foi a primeira alusão explícita de Laura Vinci à história da arte (as esculturas de ferro da década de 1990, por certo, deviam muito a Giacometti, mas não explicitamente). Mona Lisa, de 2001, foi a segunda. Retomava a ambição de Leonardo de pintar o diáfano, sobrepondo inúmeras camadas de tinta até gerar, quase literalmente, um volume de ar entre o olho e as figuras - outra tentativa de conciliação, nesse caso simbiose, entre arte e natureza. A instalação de Laura Vinci tornava visível o ar pela evaporação de água contida em bacias de vidro e esquentada por resistências, alimentadas, por sua vez, por tubos de cobre. A descrição é tão tortuosa quanto a própria obra o era. Os tubos de cobre se espalhavam como galhos ou raízes, e as bacias, dispostas desordenadamente, pareciam ter sido arrastadas por uma enchente, de maneira que o vapor, mais do que efeito, parecia causa de um microclima tropical. Esse caráter se tornou mais evidente no ano seguinte, quando os mesmos elementos foram incluídos na instalação Estados (São Paulo, Centro Cultural Banco do Brasil). No saguão do antigo banco, o diálogo com a arquitetura foi necessariamente mais cerrado: se os tubos de cobre encontravam um parentesco imediato com os corrimãos de latão que cercam o espaço em vários níveis, as bacias de vidros se espelhavam na grande claraboia de vidro colorido que se abria acima delas. É aqui, a meu ver, nessa troca a distância de reflexos, que a pesquisa de Laura Vinci se embate finalmente com a luz.

Mas, de novo, antes de enfrentar de- finitivamente a questão, há outros desdobramentos. Um, que me interessa especialmente, é $A$ máquina do mun$d o$, montada pela primeira vez em Siena em 2004 e remontado, com variações, na Bienal do Mercosul (Porto Alegre, 2005) e na Paralela de São Paulo, em 2006. Hoje integra a coleção do CAIC em Inhotim. Dessa vez, a referência não é um artista, mas um poeta, Drummond - o poema do mesmo título, incluído em Claro enigma. O trabalho marca um salto em relação à integração de arte e natureza que comentamos nas obras anteriores: o maquinário está à vista, com toda a deselegância de um industrialismo já antigo, e abre um buraco preto, rigidamente retangular, na montanha branca de pó de mármore. É como se a matéria inerte tivesse introjetado a geometria em ruína das Oficinas Matarazzo. A cavidade realmente, como quer o poema, "abriu-se majestosa e circunspecta", e a matéria assumiu para si, com dignidade um tanto resignada, a tarefa de mudar de lugar, mesmo sabendo que afinal dá no mesmo. Aquele retângulo preto é um tanto assustador, sobretudo nas versões mais enxutas de Porto Alegre e São Paulo: como se não abrisse para um interior, mas para um vazio infinito. Lembra de perto um quadro antigo, e a semelhança é tanto mais instigante enquanto talvez seja involuntária (ou, em todo caso, não declarada): refiro-me ao Enterro de Cristo de Fra Angélico.

Angélico, além de mestre da perspectiva, era excelente orador: sabia do efeito de um recorte tão abrupto, dentro de uma simetria tão estruturada. Para ele, a morte de Cristo era o fato decisivo, o corte irreversível na ordem cíclica da natureza (repare-se que as folhas das árvores são amareladas à esquerda, verdes 
à direita). Apesar de sua doçura aparente, esse pequeno painel talvez seja, junto com o Cristo morto de Mantegna, a mais pujante imagem da morte que o Renascimento nos deixou. Lembra também, além da Máquina do mundo, a caixa recoberta de borracha e piche que Joseph Beuys produziu em 1957; um espaço isolado que tudo absorve - luz, som, energia -, uma espécie de negação absoluta. Mas do buraco da Máquina do mundo sai uma esteira carregando matéria: ao se desfazer por dentro, a montanha pare outra montanha. $\mathrm{O}$ ciclo se repete impiedoso e aparentemente inútil, mas enfim: é nisso que estamos. E a instalação sugere que nesse ciclo exista um lado obscuro, uma região da morte que só se revela às vezes, e por negação.

Finalmente, a luz. Clara Clara foi montado pela primeira vez em Melbourne em 2006, num daqueles bicos altos e estreitos típicos das cidades anglo-saxônicas, para onde dão os fundos de velhos prédios de tijolos e por onde, nos filmes americanos, fogem os bandidos. Foi remontado agora no centro de São Paulo, numa rua também curta e estreita. É muito simples: cachos de luzes (luminárias comuns, daquelas protegidas por uma armação de ferro que se usam em espaços abertos) são recolhidos em redes suspensas às cornijas dos prédios. À noite, não há outra iluminação: tem-se a impressão de que as luminárias caíram de seus lugares costumeiros e ficaram presas aí, e, não sei em Melbourne, mas em São Paulo, onde grande parte da fiação ainda é a céu aberto e tem amiúde um aspecto de gambiarra, a situação parece quase plausível. Mas a rede sugere também a captura de seres vivos, talvez anjos ou estrelas caídas, ou uma pesca milagrosa de almas, ou vagalumes. Talvez, porém, a instalação revele melhor seu significado de dia, possivelmente num dia nublado. As lâmpadas, então, não iluminam mais nada, a luz fica grudada nelas como uma espécie de gosma amarelada. Finalmente vemos a luz, não algo iluminado ou que ilumina, nem mesmo um raio de luz, mas uma luz-coisa, uma luz-matéria.

Entre as duas montagens de Clara Clara, Laura Vinci enfrentara mais uma vez a questão da luz, numa obra que se chama, justamente, Lux (São Paulo: Capela do Morumbi, 2008): cachos de vasos de cristal suspensos a aros circulares. Não havia iluminação especial, mas os cristais refletindo um a outro se embebiam da luz ambiente, pareciam sugá-la e acelerá-la, como num redemoinho. Exatamente o contrário acontece em Clara Clara: a instalação emite luz, mas a luz para, fica presa nela. Se Lux remete ao jogo de reflexos das bacias de vidro de Estados, Clara Clara remonta mais atrás, às telas que Laura Vinci produzia em início de carreira. Entre elas, uma das séries mais bem-sucedidas se intitulava O quarto (1987). Outras telas pouco posteriores não têm título, mas repetem substancialmente a mesma estrutura. São listras finas, claras (amarelas, vermelhas, às vezes literalmente metálicas, de estanho) sobre fundo escuro, ou vice-versa. Quanto são linhas escuras no claro, parecem caixilhos ou assoalhos apenas visíveis em aposentos inundados de luz; quando são claras no escuro, frestas de luz num quarto fechado. Todos nós temos a experiência dessa luz debaixo da porta, que é bem visível, mas não consegue entrar, e fica aí, meio frouxa, com seu amarelo de ovo mexido. Ou então a luz leitosa que invade o quarto e apaga tudo como uma neblina, quando de repente abrimos uma janela. 
Nos dois casos, é uma luz objetivada, que não se transmite, mas, ao contrário, veda ou estanca. O mesmo acontece em Clara Clara, de dia e de noite. A luz é um dado sensível cuja natureza profunda é pôr em relação duas coisas: o sujeito que olha e o objeto que é olhado. Quando ele mesmo se torna coisa, deixa de ser o que é. Vemos finalmente a luz, mas ela não ilumina. Justamente, diria Totò.

Lorenzo Mammi é professor do Departamento de Filosofia, da Faculdade de Filosofia Letras e Ciências Humanas, da Universidade de São Paulo.

@-mammi@uol.com.br

I Faculdade de Filosofia, Letras e Ciências Humanas, Universidade de São Paulo, São Paulo/SP, Brasil. 